isolated fields. If so, exploration and exploitation are bound to be more expensive.

The official date of the first delivery of North Sea gas (from B.P., Ltd.) is July 1967, but the Gas Council hopes to start bringing small amounts ashore in the New Year. The Council is also going ahead with its plans to convert existing appliances, using natural gas piped from Algeria at $6 \cdot 25$ pence a therm, which indicates that it is serious in its intentions to exploit the North Sea. The Council estimates that it will take 10 years to convert the whole of Britain and that the cost for conversion of domestic appliances will be about $£ 30$ a household.

Even if it had to pay 5 pence a therm for North Sea gas, the consumer and the Gas Council would still benefit, but obviously the Council has set its heart on more glittering goals than that. Perhaps it should remember that after Cinderella had lost her shoe at the ball, she had to weit for it to be identified.

\section{Uncertainty of Dying}

How accurate are death certificates? A surver by M. A. Heasman and L. Lipworth (Accuracy of Certification of Cause of Death, H.M.S.O., £l ls.) suggests that there is some way to go before they can be considered as precise measurements. The survey was a large scale follow up of a pilot study undertaken in 1956 which showed that the cause of death diagnosed by clinicians agreed with that given after autopsy by a pathologist in only 51 per cent of the 1,404 cases. The new survey covered 14,617 deaths and comes to much the same conclusions as the pilot survey, though with a much greater wealth of detail.

Seventy-five hospitals took part in the survey and contributed details of all in-patients dying between March and August 1959. The clinician responsible for the patient recorded his estimate of the cause of death and an autopsy was then carried out, after which the pathologist entered his findings, presumably more accurate. Autopsies were carried out in only 65 per cent of cases, partly because the next of kin did not always agree to an autopsy and partly because some of the clinicians also took an autopsy when they were uncertain about the cause of death. The doctors involved had also to state how much weight they themselves placed on the diagnosis; whether they were "fairly certain" about it, or whether it was "probable" or "uncertain".

The clinician and the pathologist agreed about the underlying cause of death in only $45 \cdot 3$ per cent of 9,501 eases and, not surprisingly, these tended to be diagnoses about which they were "fairly certain". Half the disagreements arose because of the system of classification, based on the International Statistical Classification of Disease. In many cases, closely similar syndromes are classified as separate diseases, which tends to accentuate minor differences of wording in the diagnoses. In only a quarter of the cases were there real differences about the facts. The overall numbers of deaths ascribed to a particular cause by pathologists and clinicians tended to be similar, and thus to cancel out differences in individual diagnoses.

Some of the problems of diagnosis are obvious, such as the difficulty of knowing the primary focus of an advanced metastasized cancer. Another well known problem is the diagnosis of deaths from senile processes, and the authors suggest that provision should be made in the system of classification for such multiple cause syndromes; this would undoubtedly improve the accuracy of the mortality statistics. Some discases are more common than the death statistics would indicate. Remarkable among these, considering how conscious people are about it, is lung cancer. Others include cancers of the gallbladder and bile ducts and peptic ulcer. Cerebrovascular disease, on the other hand, is obviously a popular holdall classification, and clinicians tend to diagnose it more frequently than is justified.

One of the puzzling features of the survey is the seven years taken to publish it. In view of its obvious importance to public health studies and in epidemiology, this seems a very long time to wait.

\section{Werner Centenary}

Dr. H. Cragg writes: Alfred Werner, the founder of modern co-ordination theory, was born at Mülhausen in Alsace on December 17, 1866-exactly one hundred vears ago. His first introduction to chemistry came during his term of military training, when he attended the Technical College at Karlsruhe. From there, in 1886, he moved to the Technical High School in Zurich and studied under men such as Lunge, Hantzsch and Tredwell. It was to Lunge that he became assistant after obtaining a diploma of the college. In 1892 he worked with Berthelot for a short time, and then returned to Zurich where he published Beiträge zur Konstitution anorganischer Verbindunger (1893). The impact of this work was such that by 1895 he had progressed to a professorship.

It had been thought, for many years, that the classical theory did not fully describe compounds of the type $\mathrm{CoCl}_{3} \cdot 6 \mathrm{NH}_{3}$. In such compounds, Werner suggested, the central metal atom (cobalt in this case) could through "secondary valencies" co-ordinate itself to atoms or molecules up to a number of six and in so doing form a stable co-ordination compound. Thus he reformulated the cobalt complex as $\mathrm{Co}\left(\mathrm{NH}_{3}\right)_{6} \mathrm{Cl}_{3}$. The existence of the three chloride ions was demonstrated by precipitation with silver nitrate. He then proceeded to expand his theory to give an explanation of the arrangement of groups round a central metal atom in a co-ordination compound, and this in turn led to his prediction of stereoisomers in compounds of the type $\mathrm{Co}\left(\mathrm{NH}_{3}\right)_{4} \mathrm{X}_{2}$ on the assumption that the six radicals have an octahedral arrangement round the central metal atom, that is
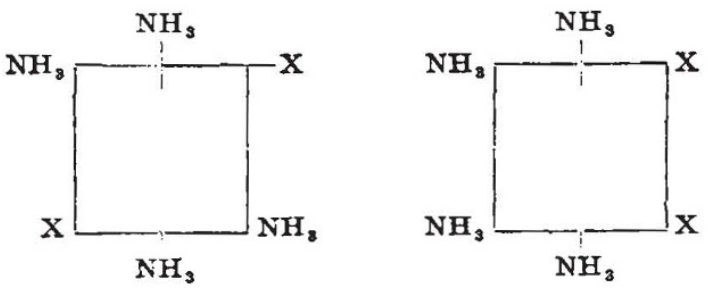

Using ethylenediamine as one of his co-ordinating groups, Werner demonstrated optical isomerism and in 1911 resolved $\left[\mathrm{Co}\left(\mathrm{NH}_{3}\right) \mathrm{en}_{2} \mathrm{Cl}\right] \mathrm{X}_{2}$ and $\left[\mathrm{Co} \mathrm{en}_{2} \mathrm{NO}_{2} \mathrm{Cl}\right] \mathrm{X}$. thus proving the validity of this theory. For his work he was awarded the Nobel Prize in 1913. He died on November 15, 1919, and since then, on the basis of his ideas, optical activity has now been demonstrated by more than twenty elements. 